\title{
ASSESSMENT OF THE SITUATION AND REMEDIATION MEASURES OF CHILDREN INSTITUTION " DOLORES " IN BELGRADE
}

Nevena Džodić ${ }^{1}$

UDK : 69.059.2:624.131.53

DOI:10.14415/konferencijaGFS2017.022

Summary: This paper presents the assessment of damaged building built on sloping ground on the basis of the position and orientation of cracks recorded. It is believed that the damage to the building occurred as a result of landslides activation.

Keywords: assessment of the situation, terrain configuration, landslide , cracks , barbicans.

\section{BASIC INFORMATION ABOUT THE BUILDING}

The building of Combined children's institution was built on very steep terrain configuration and was therefore designed in two floor levels GF +1 (ground floor and first floor ) facing to the street Milica Srpkinja , and in levels GF +2 to the courtyard, due to terrain in the slope, so that the object has a " sawtooth " form. Base of the facility is approximatelly square shaped, measuring about $28.9 \times 24.7 \mathrm{~m}$, with ground floor area of $430 \mathrm{~m}^{2}$ and the floor area of $484 \mathrm{~m}^{2}$. The structural system is massive, brick walls are $38 \mathrm{~cm}$ and $25 \mathrm{~cm}$ thick, with a stiffening from $\mathrm{AB}$ horizontal and vertical ring beams and reinforced $A B$ wall panels. The floor structure is full $A B$ slab $d=14-20 \mathrm{~cm}$, except in the events hall ,due to higher ranges where the coffered ceiling with cassette 100x100 $\mathrm{cm}$ was adopted. The roof plate is also full $\mathrm{AB}$ plate. The foundations are the ribbon cascading. Under the foundation a buffer layer of gravel was provided. No information available on geotechnical investigation works . Data on systematic subsidence are not available. Around the building were made pavements $1.0 \mathrm{~m}$ wide.

\section{FIELD INSPECTION - ASSESSMENT SHEET ( 2008 year )}

The building was built on a natural slope, but according its structure the centre of gravity of the entire building ( center of mass ) is placed in the lower part of the slope, which is unfavorable for this configuration of the terrain. If the surface of the ground is not horizontal the component of the gravity force appears, which tends to move down the mass of soil . Most likely it is a object built on the landslide that was activated due to inadequate drainage of rainwater and water penetration into the part of the building that

\footnotetext{
${ }^{1}$ Nevena Bošković C.E., Arch.E., Civil Engineering School, Belgrade, Sv.Nikola street, Serbia, , тел: 011 2417680, e - mail: nevena_boskovic@ymail.com
} 
is on embankment. The building is made in a wide excavation and the part of low ground that is not under the building is covered (to the street Milica Srpkinja). Due to the penetration of water laid material was loosened (poor compaction), and there was damage of the ground slabs on the ground floor, rooms 25, 26, 27, 28. Rooms above are not damaged, which indicates that foundations were not relented. Characteristically for landslides recognition is appearance of the cracks at the top of the slope and withdrawal down of structures and soil, and in the bottom of the building appearance of cracks upward (the formation of a sliding body).
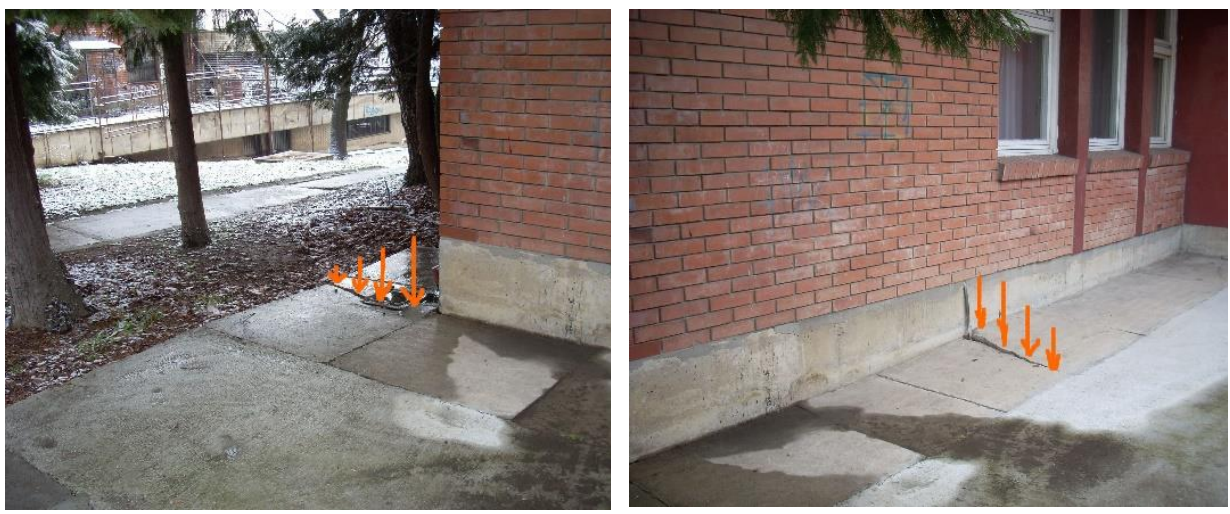

Figure 1. Cracks at the top of the slope
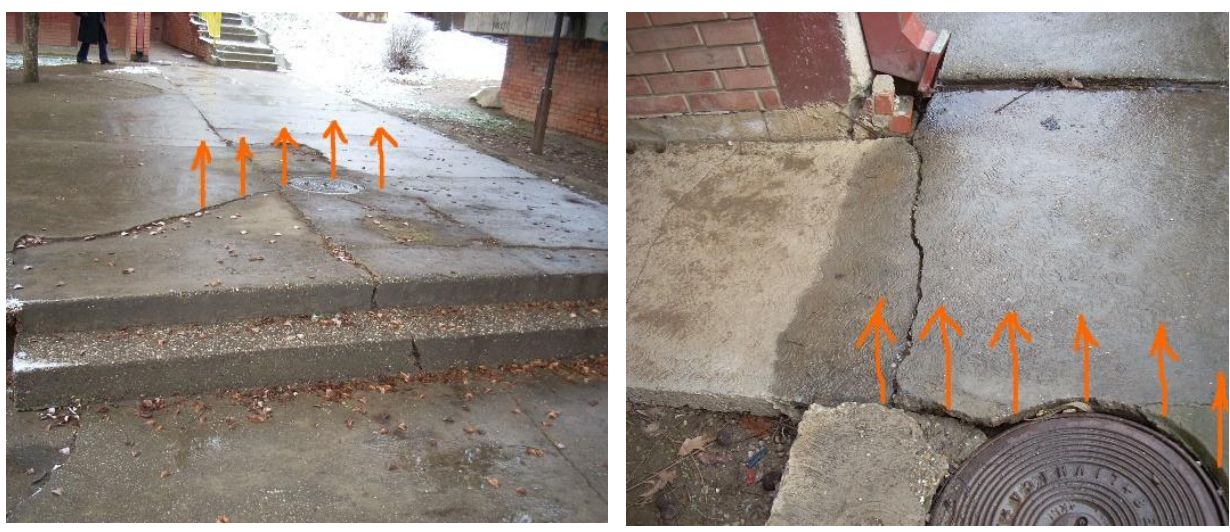

Figure 2. Cracks at the slope base

This is probably the case of the sliding body weight increasing due to the construction of the building on a natural slope (weight on the slope increased), followed by the penetration and action of rainwater. On the retaining wall were not made barbicans (circular openings in the retaining wall) through which takes place the drainage of water 


\section{$5^{\text {th }}$ INTERNATIONAL CONEERENCE}

Contemporary achievements in civil engineering 21. April 2017. Subotica, SERBIA

which failed to be collected by rainwater sewers. Before the start of the repair works it is necessary to drill the retaining wall at the economic entrance at height of $0.5 \mathrm{~m}$ from the level of the entrance, with diameter $\varnothing 100$ at a distance $1.20 \mathrm{~m}$, and by prefabricated gutter lead to the level of street storm sewers.
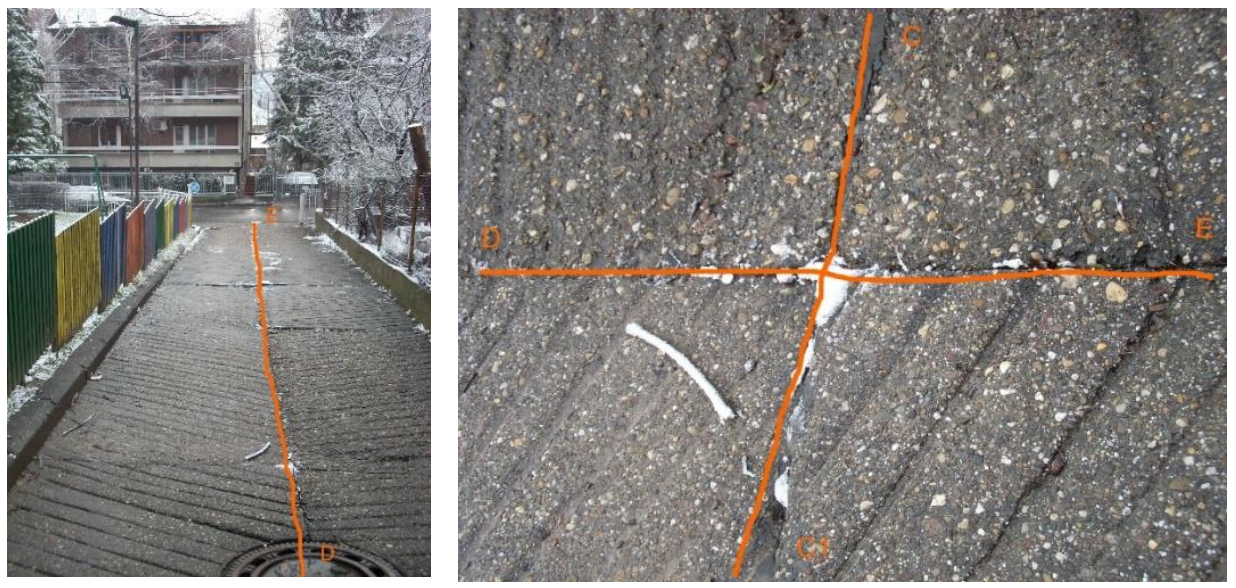

Figure 3. Rotation axes of sliding body - characteristic longitudinal cracks, shearing
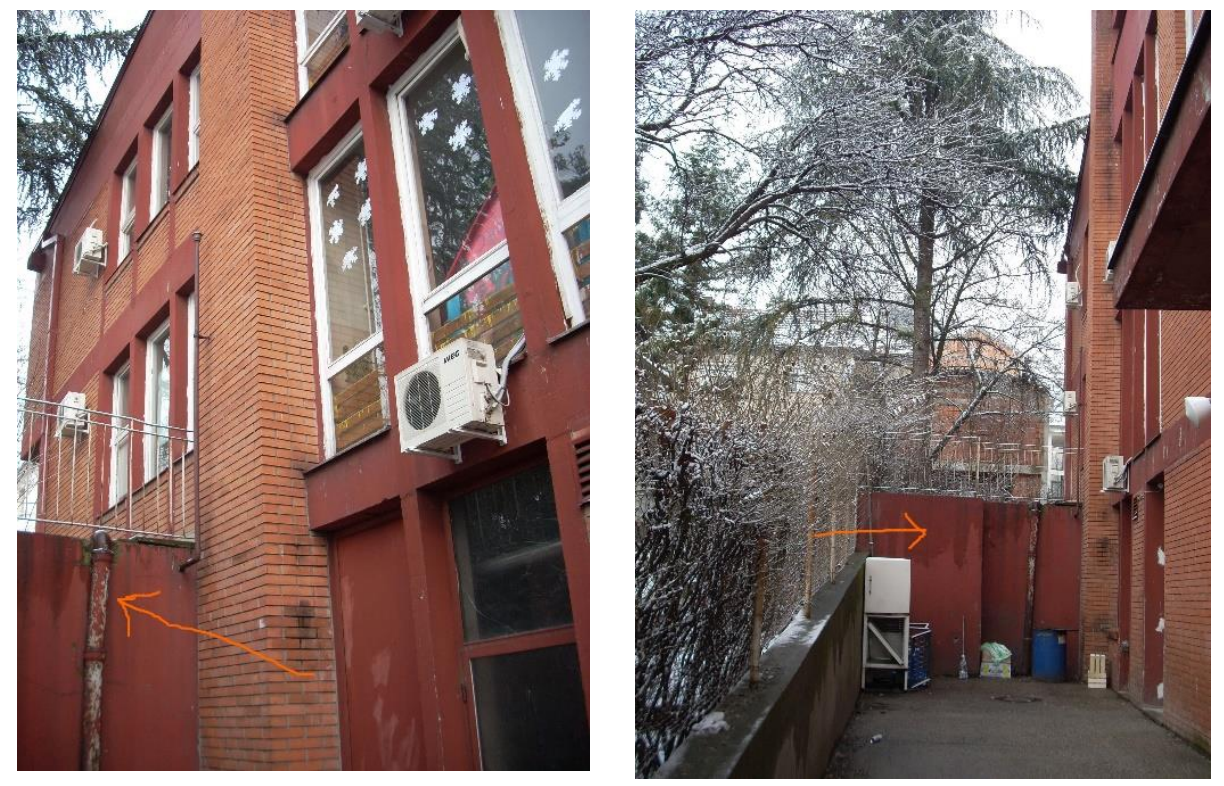

Figure 4. Retaining wall at economic entrance 


\section{THE CAUSES OF SLIDING}

The ground sloped will be in balance if the shear strength for each point of sliding plane is greater than the shear stress .

In the simplest case, when the slope is not saturated with water and unencumbered by external forces, the forces acting on the sliding body ( Figure 5) are the weight of the soil $\mathrm{W}$, the normal component of the reaction to the sliding surface Fn, shear force Ft and S shear resistance along the sliding surface. These three forces are arranged in force polygon. If Ft is greater than S, the sliding will occur. In the case that the slope was fully submerged in the water and was long under these conditions, then, in addition to the force $\mathrm{S}, \mathrm{W}, \mathrm{Fn}$, there will exist the hydrostatic pressure on the surface of the slope and the sliding surface. Their resultants are $\mathrm{P}_{\mathrm{w} 1}$ and $\mathrm{P}_{\mathrm{w} 2}$. Forces polygon suggests that the combined action of $\mathrm{P}_{\mathrm{w} 1}$ and $\mathrm{P}_{\mathrm{w} 2}$ reduces $\mathrm{W}$ to $\mathrm{W}^{\prime}$ is increasing (weight of soil soaked in water ). Value of $\mathrm{Ft}$ is significantly lower than in the first case, but the $\mathrm{S}$ is lower also.

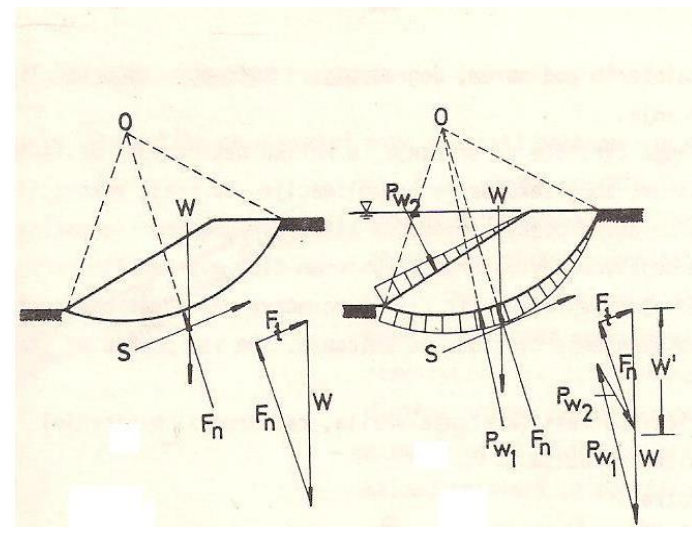

Figure 5. Impact on sliding body

Instability of earth and rock masses may appear in a number of diverse forms. The ability to predict these phenomena, assessment of possible displacement rates and the size of the area that it will be exposed in the event of the occurrence of instability, are not subjected to a unique and simple methodology, nor a single technical discipline. Identification of problem enables finding of practical solution in particular circumstances, where, in the event of natural, but also carried out slopes, is necessary to establish their eventual "activity" with the size, direction and speed of its displacement.

The first and primary remedial measure would be rehabilitation of landslides. To determine the activity and rehabilitation measures surveying the terrain should be made, and then the geotechnical investigation works in order to provide reliable information on the ground in the building area. The aim is to determine the spatial position (depth, thickness and spreading) of the individual layers of the soil and the groundwater level. The geological mapping is necessary in order to determine the geological profile of the 


\section{$5^{\text {th }}$}

Contemporary achievements in civil engineering 21. April 2017. Subotica, SERBIA

soil and the groundwater level. Since there is no construction project, it is necessary to carry out investigative works to determine the depth and dimensions of the foundation as well as the demolition of elements specified by the designer to determine the diameter and number of reinforcement bars. After the obtained following data:

- Geodetic survey of the terrain

- Geological soil profile

- The level of groundwater

- Activity and classification of slope

- Research works for determining the dimensions and depth of the foundations have to make the main project of rehabilitation of ground slab and landslides.

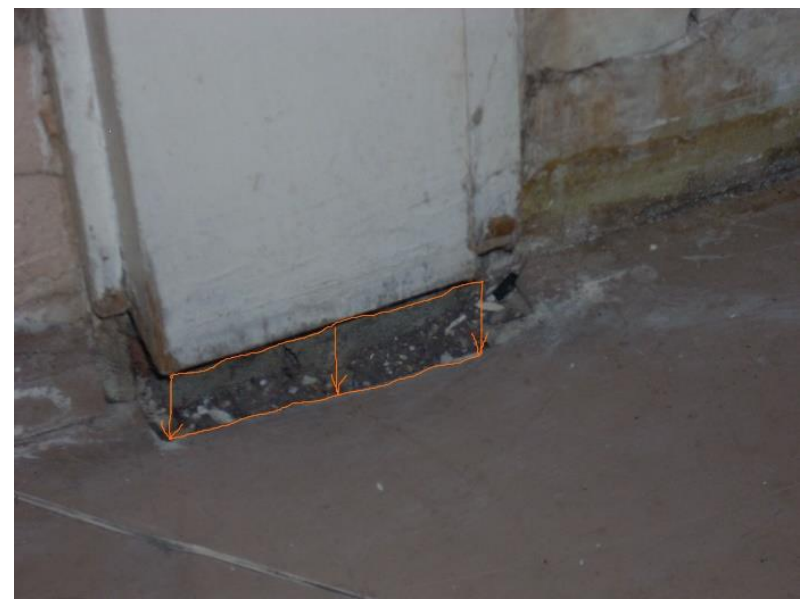

Figure 6. Ground slab in the ground floor between rooms 26 and 27

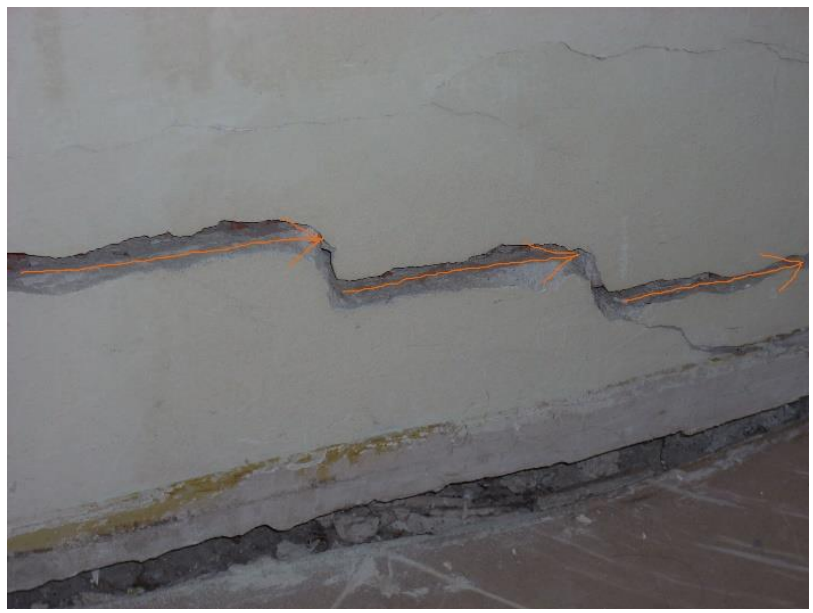

Figure 7. The cracks on the wall of the room 26 keep track of the terrain slope 


\section{CONCLUSIONS}

At rehabilitation of facilities built on natural slopes, by the analysis of the position and direction of propagation of cracks can be concluded whether the degradation of the object caused by landslides activation. When the building is designed on a natural slope, attention must be taken that the center of gravity of the object mass being set up in that way to stabilize the slope. Landslides activation usually occurs as a result of poor distribution of the object mass. Figure 8 shows the condition of the retaining wall in 2008 . It was created passive central and active block without cracks opening.

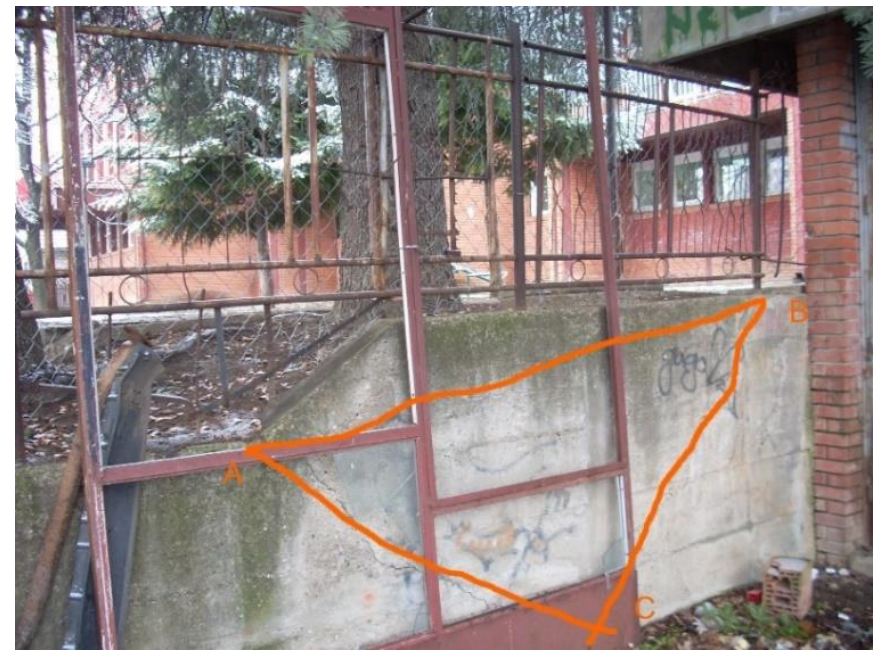

Figure 8. Condition of the retaining wall in 2008
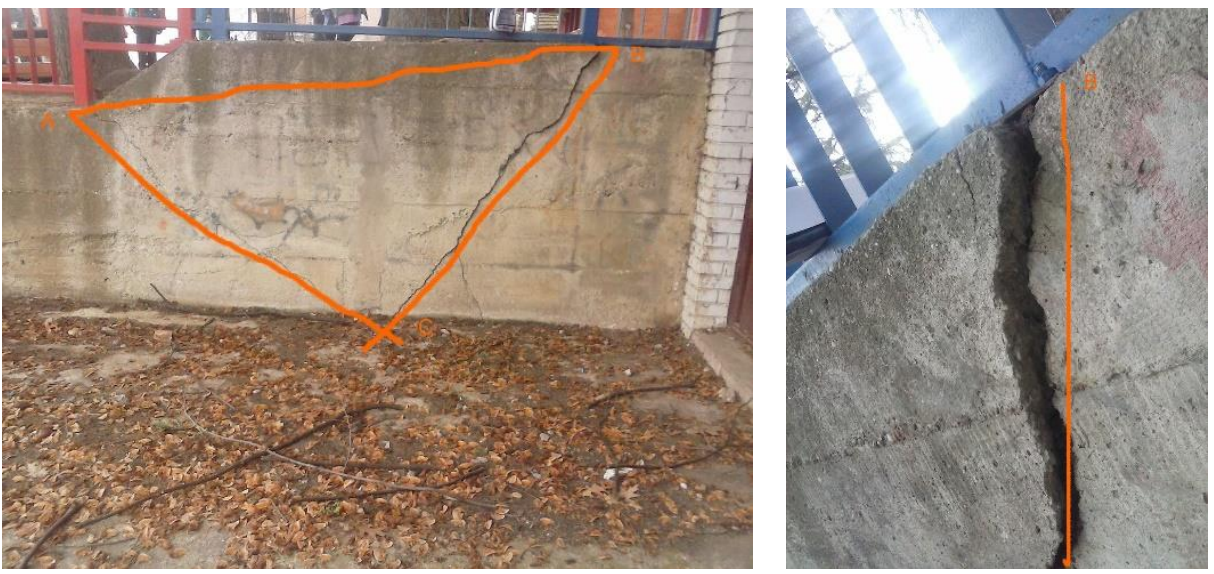

Figure 9. Condition of the retaining wall in 2016 


\section{$5^{\text {th }}$ inTERNATIONAL CONFERENCE}

Contemporary achievements in civil engineering 21. April 2017. Subotica, SERBIA

Condition of retaining wall 2016. (Formed sliding plane - sliding along the axis CC 1 open cracks about $7 \mathrm{~cm}$ ). Figure 10 shows that after the rehabilitation in December 2015, there is no cohesion in the direction $\mathrm{CC} 1 \mathrm{c}=0$.

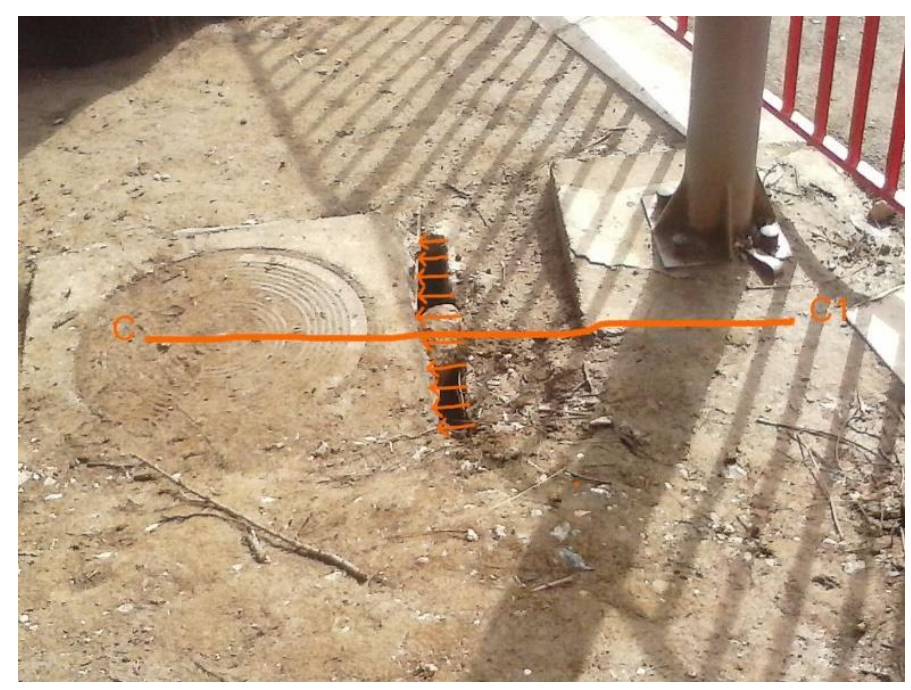

Figure 10

\section{REFERENCES}

[1] Dr Radoslav Stojadinovic: Soil Mechanics 2, Science book (Naucna knjiga), Belgrade, 1986, p.381, Fig.5.4.

[2] The main architectural project made 1977 in Project buerau Contemporary architecture from Belgrade. 